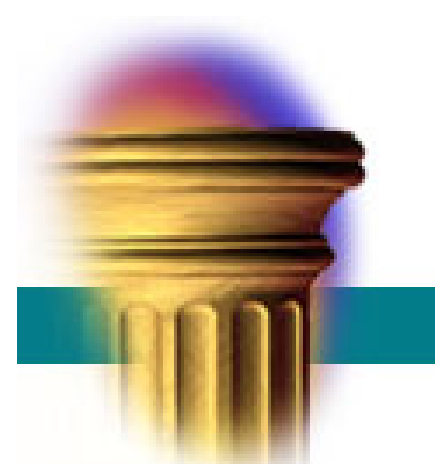

\title{
○ \\ Monetary and Fiscal Policies in Times of Large Debt: Unity is Strength
}

Francesco Bianchi, Renato Faccini, and Leonardo Melosi

\author{
REVISED \\ May 11, 2020
}

WP 2020-13

https://doi.org/10.21033/wp-2020-13

${ }^{*}$ Working papers are not edited, and all opinions and errors are the responsibility of the author(s). The views expressed do not necessarily reflect the views of the Federal Reserve Bank of Chicago or the Federal Reserve System. 


\title{
Monetary and Fiscal Policies in Times of Large Debt: Unity is Strength*
}

\author{
Francesco Bianchi \\ Duke University \\ CEPR and NBER
}

\author{
Renato Faccini \\ Danmarks Nationalbank \\ Queen Mary, University of London \\ Centre for Macroeconomics (LSE)
}

\author{
Leonardo Melosi \\ FRB Chicago \\ EUI and CEPR
}

May 11, 2020

\begin{abstract}
The COVID pandemic found policymakers facing constraints on their ability to react to an exceptionally large negative shock. The current low interest rate environment limits the tools the central bank can use to stabilize the economy, while the large public debt curtails the efficacy of fiscal interventions by inducing expectations of costly fiscal adjustments. Against this background, we study the implications of a coordinated fiscal and monetary strategy aiming at creating a controlled rise of inflation to wear away a targeted fraction of debt. Under this coordinated strategy, the fiscal authority introduces an emergency budget with no provisions on how it will be balanced, while the monetary authority tolerates a temporary increase in inflation to accommodate the emergency budget. In our model the coordinated strategy enhances the efficacy of the fiscal stimulus planned in response to the COVID pandemic and allows the Federal Reserve to correct a prolonged period of below-target inflation. The strategy results in only moderate levels of inflation by separating long-run fiscal sustainability from a short-run policy intervention.
\end{abstract}

JEL Codes: E50, E62, E30.

Keywords: Monetary policy, fiscal policy, emergency budget, shock specific rule, COVID.

\footnotetext{
*Emails: francesco.bianchi@duke.edu, rmmf@nationalbanken.dk, and lmelosi@frbchi.org. We thank Jonas Fisher and Federico Ravenna for their very helpful suggestions. The views in this paper are solely those of the authors and should not be interpreted as reflecting the views of the Federal Reserve Bank of Chicago, Danmarks Nationalbank, or any person associated with the Federal Reserve System or the European System of Central Banks.
} 


\section{Introduction}

The COVID pandemic found policymakers facing constraints on their ability to react to an exceptionally large negative shock. The current low interest rate environment limits the tools the central bank can use to stabilize the economy following adverse shocks. The US economy has experienced a prolonged period of below-target inflation and it is now back to the zero lower bound as a result of the COVID shock. At the same time, the record high debt level may curtail the efficacy of fiscal interventions by inducing expectations of costly fiscal adjustments. In January 2020, the Congressional Budget Office (CBO) estimated that, under current law, Federal debt at the end of this decade would be higher as a percentage of GDP than at any time since 1946. If no fiscal adjustment is made, debt will continue to increase and in 2050 will be higher than the highest level ever recorded in the United States. High and increasing federal debt would reduce national saving and income, limit the ability of policymakers to respond to unforeseen events, and increase the likelihood of a fiscal crisis.

The recent fiscal stimulus of $\$ 2.6$ trillion dollars and the recession caused by the restrictive measures taken by authorities in many states to contrast the spreading of COVID-19 are exacerbating this already strained fiscal situation. The debate over widening fiscal imbalances, and what to do about them, is likely to move toward the center of the political agenda after the pandemic crisis is over. Expectations of fiscal corrections and of diminished fiscal space in the next recession could be a heavy drag on economic activity. In fact, such expectations may diminish the effectiveness of the recent fiscal stimulus.

In this paper, we analyze a policy that involves coordination between the monetary and fiscal authorities to inflate away a fraction of the large public debt. In the coordinated policy, the fiscal authority ascribes the fiscal interventions in response to COVID-19 to an emergency budget, and the monetary authority replaces its perfectly symmetric strategy of inflation stabilization with a temporary increase in the inflation target. We find that this policy enhances the effectiveness of fiscal stimulus and correct a two-decade-long period of below-target inflation, thereby expanding the limited leeway that fiscal and monetary authorities have when acting in isolation.

An important historical precedent that shares some similarities with the approach studied in this paper is President Roosevelt's New Deal. In 1933, President Roosevelt openly argued that there were two separate budgets. A regular federal budget for which a pledge was made to cut specific outlays to guarantee its fiscal backing. An emergency budget, which was needed to defeat the depression and which was unbalanced. In April of the same year, the United States abandoned the gold standard, delinking the value of the dollar to gold and reclaiming autonomous monetary policy. 
We introduce the notion of emergency budget into an otherwise state-of-the-art dynamic general equilibrium model to illustrate the effects of adopting this new monetary and fiscal setting. The model features a rich fiscal block with distortionary taxation on labor and capital income. Unlike a typical model, the fiscal authority has two budgets. A regular budget, backed by future fiscal adjustments, and an emergency budget. The fiscal authority is committed to repay the debt ascribed to the regular budget following the orthodox approach -by increasing tax rates on labor, capital and consumption and by cutting government spending. Yet, the fiscal and monetary authorities agree on working together to stabilize the jump in the emergency budget resulting from the $\$ 2.6$ trillion stimulus package. The introduction of a time-varying short-term inflation goal clarifies to the public that the monetary authority is willing to coordinate its policy with the fiscal authority and tolerate inflation above the long-run two-percent target for some time. The exact amount of tolerated inflation is the one that is needed to wear away the desired amount of debt. The concerted actions of the two authorities make such path for inflation credible because needed to stabilize the amount of debt in excess of the regular budget.

This new setting causes a rapid stabilization of the debt-to-GDP ratio mainly because it generates an economic boom. Thus, while the $\$ 2.6$ trillion 2020 stimulus bill is the largest U.S. fiscal stimulus on record, we find that the decision of ascribing it to the emergency budget results in just a modest increase in inflation. A general equilibrium effect explains this result: the economic boom ensuing the introduction of the new regime significantly contributes to lowering the debt-to-GDP ratio and hence inflation does not have to rise exorbitantly to wear away the debt ascribed to the emergency budget. Indeed, after a rapid but contained increase, inflation falls, remaining slightly heightened for several years. Such a persistent effect on inflation raises nominal interest rates reducing the risk for the economy to fall into a liquidity trap. In the short run, the rapid increase in inflation lowers real interest rates and improves the ability of policymakers to shore up the economy from the COVID recession.

We then discuss the implications of two alternative scenarios, in which the Central Bank refuses to share any responsibility in ensuring the stability of debt. First, we compare the outcome of our policy proposal to the one in which policymakers follow the orthodox approach of raising taxes and cutting expenditures to reduce the debt-to-GDP ratio. The orthodox approach dwarfs the expansionary effects of the fiscal stimulus on output and has very long-lasting contractionary effects, depressing economic activity for a considerable number of years. This economic slowdown partially defies the government's effort to reduce the debt-to-GDP ratio, resulting in a much longer period of fiscal consolidation compared to the approach analyzed in this paper. 
Alternatively, inaction could result in expectations of high inflation if agents become convinced that the fiscal authority will not be able to rein in debt via fiscal adjustments and might be tempted to coerce the central bank to create inflation to stabilize the entirety of debt. In this scenario, the central bank effectively loses control of inflation and any attempt to stabilize it could backfire. The economy experiences high inflation and a substantial increase in macroeconomic volatility because the economy is no longer insulated with respect to fiscal imbalances. By adopting a coordinated strategy based on the introduction of an emergency budget instead, policymakers would remove uncertainty about the future and limit the inflationary consequences of the policy intervention. This is the result of separating the issue of long-run fiscal sustainability from a stabilization policy. In fact, policy coordination might be the only way to preserve central bank independence in the long run.

This paper is connected to the vast literature on monetary-fiscal policy interaction (Sargent and Wallace 1981; Leeper 1991; Sims 1994; Woodford 1994, 1995, 2001; Cochrane 1998, 2001; Schmitt-Grohe and Uribe 2000; Bassetto 2002; Reis 2016; among many others). Monetary-fiscal policy interaction is modelled based on monetary and fiscal policy rules as in Leeper (1991). Bianchi and Melosi (2019) introduced the concept of shock specific rules as a way to resolve a conflict between the monetary and fiscal authorities in presence of a high fiscal burden that the fiscal authority is reluctant or unable to stabilize. This notion of shock-specific rules proves to be useful to solve models in which monetary and fiscal authorities adopt state-dependent targets, like in the case of the emergency budget studied in this paper. In this paper, we introduce an emergency budget into a state-of-the-art DSGE model with a rich fiscal block as a solution to a situation of impasse due to high distortionary taxation and a low interest rate environment. We highlight that absent coordination between the two authorities, a large fiscal stimulus might result in a disappointing economic performance. This is because distortionary taxation and the inability of the central bank to operate smoothly once at the zero lower bound represent a drag on the economy, even if no conflict between the two authorities arise.

Our work is also related to Woodford (2003) and Benhabib, Schmitt-Grohe, and Uribe (2002) who show that liquidity traps can be made fiscally unsustainable. Furthermore, the shock-specific rule that we investigate shares some features with the policy interventions that Chris Sims has advocated at the 2016 Jackson Hole meeting to replace ineffective monetary policy at the zero lower bound (Sims 2016). Concisely, Sims argues that policymakers should make clear that fiscal policy also aims at achieving a certain level of inflation. Unlike Sims' proposal, our shock specific rule outlines the amount of debt that policymakers are planning to stabilize with inflation and links such amount to one particular event, the fiscal stimulus in response to the COVID-19 pandemic. This is an important distinction that limits the 
amount of inflation generated by the coordinated policy strategy analyzed in this paper. Once the shock is reabsorbed, the economy naturally reverts back to the pre-crisis policy framework.

Hall and Sargent (2011) show that historically most of US debt stabilization has been achieved through a combination of growth, revaluation effects, and low real interest rates, while changes in primary surpluses played a relatively modest role. Bianchi and Ilut (2017) link the high inflation of the 1970s to a Fiscally-led regime in which the monetary authority accommodates the behavior of the fiscal authority. Bianchi and Melosi (2017) argue that the possibility of a return to such regime can explain the lack of deflation in the aftermath of the Great Recession. Leeper, Traum, and Walker (2017) find that monetary-led and Fiscally-led regimes return similar fit when a DSGE model is estimated on post-WWII US data. Thus, there is evidence that the post-Volcker monetary-led policy mix characterized by ample central bank independence has not always been the norm. The shock-specific rule studied in this paper can be thought as a way to remove the risk of a tout court return to a Fiscally-led strategy, in which the monetary authority is required to systematically create inflation to stabilize government debt. ${ }^{1}$ Such change would lead to very high levels of inflation and macroeconomic volatility.

The paper is organized as follows. Section 2 and Section 3 present the model and its calibration, respectively. Section 4 lays out the strategy of our quantitative analysis and presents the main results. In Section 5, we compare the economic implications of the emergency budget strategy with a tout court switch to a Fiscally-led regime, a scenario in which the central bank loses its independence and create inflation to stabilize the large post-COVID-19 public debt. Section 6 contains our concluding remarks.

\section{The Model}

We extend a version of the medium scale general equilibrium model estimated by Leeper, Traum, and Walker (2017) to account for shock specific rules along the lines of Bianchi and Melosi (2019). Namely, the environment consists of an economy a la Christiano, Eichenbaum, and Evans (2005), augmented with distortionary taxes on labor, capital and consumption, and a rich fiscal block. With respect to a typical model, both monetary and fiscal policy rules are specified with respect to a regular budget and an emergency budget. In what follows, we outline the model in detail.

\footnotetext{
${ }^{1}$ See Bassetto (2002) for a seminal study of the game theoretical aspects of the interactation between the monetary and fiscal authorithies.
} 


\section{$2.1 \quad$ Households}

The economy is populated by a unit measure of households, of which a fraction $\mu$ are handto-mouth consumers. The remaining fraction, $1-\mu$, are savers and we indicate them with an $S$ superscript. Hand-to-mouth households are assumed in the model as a simple way of breaking the Ricardian equivalence, making transfers relevant for a fraction of the population.

Savers A household of optimizing saving agents, indexed by $j$, derives utility from the consumption of a composite good, $C_{t}^{* S}(j)$, which comprises private consumption $C_{t}^{S}(j)$ and government consumption $G_{t}$ such that $C_{t}^{* S}(j)=C_{t}^{S}(j)+\alpha_{G} G_{t}$. The parameter $\alpha_{G}$ governs the substitutability between private and government consumption. When negative, the goods are complements; when positive, they are substitute. External habits in consumption imply that utility is derived relative to the previous period value of aggregate savers' consumption of the composite good $\theta C_{t-1}^{* S}$, where $\theta \in[0,1]$ is the habit parameter. Saver households also derive disutility from the supply of differentiated labor services from all its members, indexed by $l, L_{t}^{S}(j)=\int_{0}^{1} L_{t}^{S}(j, l) d l$. The period utility function is given by $\mathcal{U}_{t}^{S}=\left(\ln \left(C_{t}^{* S}(j)-\theta C_{t-1}^{* S}\right)-L_{t}^{S}(j)^{1+\xi} /(1+\xi)\right)$, where $\xi$ is the Frisch elasticity.

Households accumulate wealth in the form of physical capital $\bar{K}_{t}^{S}$. The stock of capital depreciates at rate $\delta$ and accrues with investment $I_{t}^{S}$, net of adjustment costs. The law of motion for physical capital is: $\bar{K}_{t}^{S}(j)=(1-\delta) \bar{K}_{t-1}^{S}(j)+\left[1-s\left(\frac{I_{t}^{S}(j)}{I_{t-1}^{S}(j)}\right)\right] I_{t}^{S}(j)$, where $s$ denotes a standard investment adjustment cost function that satisfies the properties $s\left(e^{\gamma}\right)=$ $s^{\prime}\left(e^{\gamma}\right)=0$ and $s^{\prime \prime}\left(e^{\gamma}\right) \equiv s>0$.

Households derive income from renting effective capital $K_{t}^{S}(j)$ to the intermediate firms. Effective capital is related to physical capital according to $K_{t}^{S}(j)=\nu_{t}(j) \bar{K}_{t-1}^{S}(j)$, where $\nu_{t}(j)$ is the capital utilization rate. The cost of utilizing one unit of physical capital is given by the function $\Psi\left(\nu_{t}(j)\right)$. Given the steady-state utilization rate $\nu(j)=1$, the function $\Psi$ satisfies the following properties: $\Psi(1)=0$, and $\frac{\Psi^{\prime \prime}(1)}{\Psi^{\prime}(1)}=\frac{\psi}{1-\psi}$, where $\psi \in[0,1)$. We further denote the gross rental rate of capital as $R_{t}^{k}$ and the tax rate on capital rental income as $\tau_{t}^{K}$.

The household can also invest in the financial market by purchasing two types of zerocoupon bonds, which differ in their maturity. One-period bonds promising a nominal payoff $B_{s, t}$ at time $t+1$ can be purchased at the present discounted value $R_{t}^{-1} B_{s, t}$, where $R_{t}$ is the gross nominal interest rate set by the central bank. Long-term government bond $B_{t}$ with a maturity decaying at constant rate $\rho \in[0,1]$ and duration $(1-\beta \rho)^{-1}$, can be purchased at price $P_{t}^{B}$.

Each period, the household receives after-tax nominal labor income, after-tax revenues from renting capital to the firms, lump-sum transfers from the government $Z_{t}^{S}$ and dividends from the firms $D_{t}$. These resources can be spent to consume and to invest in physical capital 
and bonds. The nominal budget constraint for the saver household is:

$$
\begin{aligned}
& P_{t}\left(1-\tau_{t}^{C}\right) C_{t}^{S}(j)+P_{t} I_{t}^{S}(j)+P_{t}^{B} B_{t}(j)+R_{t}^{-1} B_{s, t} \\
= & \left(1+\rho P_{t}^{B}\right) B_{t-1}(j)+B_{s, t-1}(j)+\left(1-\tau_{t}^{L}\right) \int_{0}^{1} W_{t}(l) L_{t}^{S}(j, l) d l \\
& +\left(1-\tau_{t}^{K}\right) R_{t}^{k} \nu_{t}(j) \bar{K}_{t-1}^{S}(j)-\psi\left(\nu_{t}\right) \bar{K}_{t-1}^{S}(j)+P_{t} Z_{t}^{S}(j)+D_{t}(j),
\end{aligned}
$$

where $W_{t}(l)$ denotes the wage rate that applies to all household members, and $\tau_{t}^{C}$ and $\tau_{t}^{L}$ denote the tax rates on consumption and labor income, respectively. The household maximizes lifetime discounted utility $\sum_{t=0}^{\infty} \beta^{t} \mathcal{U}_{t}^{S}$ subject to the sequence of budget constraints in Eq.(1).

Hand-to-Mouth Households Every period, hand-to-mouth households consume all of their disposable, after-tax income, which comprises revenues from labor supply and government transfers. It is assumed that the hand-to-mouth households supply differentiated labor services, and set their wage to be equal to the average wage that is optimally chosen by the savers, as described below. Using the superscript $N$ to indicate the non-saving, hand-to-mouth households, their budget constraint can be written as follows:

$$
\left(1+\tau_{t}^{C}\right) P_{t} C_{t}^{N}(j)=\left(1-\tau_{t}^{L}\right) \int_{0}^{1} W_{t}(l) L_{t}^{N}(j, l) d l+P_{t} Z_{t}^{N}(j)
$$

where it is assumed that both savers and non savers face the same tax rates on consumption and labor income.

\subsection{Firms and Price Setting}

Final good producers A perfectly competitive sector of final good firms produces the homogeneous good $Y_{t}$ at time $t$ by combining a unit measure of intermediate differentiated inputs using the technology $Y_{t}=\left(\int_{0}^{1} Y_{t}(i)^{\frac{1}{1+\eta^{p}}} d i\right)^{1+\eta^{p}}$, where $\eta^{p}$ denotes the mark-up to the prices of intermediate goods. Profit maximization yields the demand function for intermediate goods $Y_{t}(i)=Y_{t}\left(P_{t}(i) / P_{t}\right)^{-\left(1+\eta^{p}\right) / \eta^{p}}$, where $P_{t}(i)$ is the price of the differentiated good $i$ and $P_{t}$ is the aggregate price of the final good.

Intermediate good producers Intermediate firms produce using the technology $Y_{t}(i)=$ $K_{t}(i)^{\alpha}\left(A_{t} L_{t}(i)\right)^{1-\alpha}-A_{t} \Omega$, where $\Omega$ is a fixed cost of production that grows with the rate of labor-augmenting technological progress $A_{t}$ and $\alpha \in[0,1]$ a parameter. It is assumed that technological progress $A_{t}$ grows at the constant rate $e^{\gamma}$. Intermediate firms rent capital and labor in perfectly competitive factor markets. It is assumed that $L_{t}$ is a bundle of 
all the differentiated labor services supplied in the economy, which are aggregated into a homogeneous input by a labor agency, as described below. The nominal rental rate of capital is denoted by $R_{t}^{K}$ and the wage rate by $W_{t}$. Cost minimization implies that all firms incur the same nominal marginal cost $M C_{t}=(1-\alpha)^{\alpha-1} \alpha^{-\alpha}\left(R_{t}^{k}\right)^{\alpha} W_{t}^{1-\alpha} A_{t}^{-1+\alpha}$.

When setting prices, intermediate producers face frictions $\grave{a}$ la Calvo, i.e., at time $t$ a firm $i$ can optimally reset its price with probability $\omega^{p}$. Otherwise it adjusts the price with partial indexation to the previous period inflation rate according to the rule $P_{t}(i)=$ $\left(\Pi_{t-1}\right)^{\chi_{p}}(\Pi)^{1-\chi_{p}} P_{t-1}(i)$, where $\chi_{p} \in[0,1]$ is a parameter, $\Pi_{t-1}=\frac{P_{t-1}}{P_{t-2}}$ and $\Pi$ denotes the aggregate rate of inflation at steady state.

Intermediate producers that are allowed to reset their price maximize the expected discounted stream of nominal profits:

$$
\max E_{t} \sum_{s=0}^{\infty}\left(\beta \omega_{p}\right)^{s} \frac{\Lambda_{t+s}^{S}}{\Lambda_{t}^{S}}\left[\left(\prod_{k=1}^{s} \Pi_{t+k-1}^{\chi^{p}} \Pi^{1-\chi^{p}}\right) P_{t}(i) Y_{t+s}(i)-M C_{t+s} Y_{t+s}(i)\right]
$$

subject to the demand function from the final good sector, where $\Lambda^{S}$ denotes the marginal utility of the savers.

\subsection{Wages}

We assume that both savers and hand-to-mouth households are monopoly suppliers of a unit measure of differentiated labor service, indexed by $l$. Each period, a saver household gets an opportunity to optimally readjust the wage rate that applies to all of its workers, $W_{t}(l)$, with probability $\omega_{w}$. If the wage cannot be reoptimized, it will be increased at the geometric average of the steady state rate of inflation $\Pi$ and of last period inflation $\Pi_{t-1}$, according to the rule $W_{t}(l)=W_{t-1}(l)\left(\Pi_{t-1} e^{\gamma}\right)^{\chi_{w}}\left(\Pi e^{\gamma}\right)^{1-\chi_{w}}$, where $\chi_{w} \in[0,1]$ captures the degree of nominal wage indexation. It is assumed that the hand-to-mouth households set their wage to be equal to the average wage that is optimally chosen by the savers.

All households, including both savers and non savers, sell their labor service to a representative, competitive agency that transforms it into an aggregate labor input, according to the technology $L_{t}=\left(\int_{0}^{1} L_{t}(l)^{\frac{1}{1+\eta^{w}}} d l\right)^{1+\eta^{w}}$, where $\eta^{w}$ is the wage mark-up. The agency rents labor type $L_{t}(l)$ at price $W_{t}(l)$ and sells a homogeneous labor input to the intermediate producers at price $W_{t}$. The static profit maximization problem yields the demand function $L_{t}(l)=L_{t}\left(W_{t}(l) / W_{t}\right)^{-\left(1+\eta^{w}\right) / \eta^{w}}$. 


\subsection{Government Budget Constraint}

Assuming that one-period government bonds are in zero net supply, the government nominal budget constraint can be written as:

$$
P_{t}^{B} B_{t}+\tau_{t}^{K} R_{t}^{k} K_{t}+\tau_{t}^{L} W_{t} L_{t}+\tau_{t}^{C} P_{t} C_{t}=\left(1+\rho P_{t}^{B}\right) B_{t-1}+P_{t} G_{t}+P_{t} Z_{t}
$$

where $C_{t}=\mu C_{t}^{N}+(1-\mu) C_{t}^{S}$ denotes aggregate consumption and $Z_{t}=\int_{0}^{1} Z_{t}(j) d j=Z^{S}=$ $Z^{N}$, following the assumption that lump-sum transfers are identical across households. The budget constraint in Eq. (2) implies that the fiscal authority finances government expenditures, transfers, and the rollover of expiring long-term debt by raising taxes on consumption, labor and capital, and by issuing new long-term debt obligations.

\subsection{Monetary and Fiscal Policy}

We rescale the variables entering the fiscal rules by defining $g_{t}=G_{t} / A_{t}, z_{t}=Z_{t} / A_{t}$ and we denote the debt-to-GDP ratio as the market value of outstanding debt divided by GDP $s_{b, t-1}=\frac{P_{t-1}^{B} B_{t-1}}{P_{t-1} Y_{t-1}}$. In what follows, for each variable $x$, we use $\widehat{x}$ to denote the percentage deviation from its own steady state.

We consider two cases. In the fiscal orthodoxy case, the fiscal authority is committed to repay the entirety of public debt with future fiscal adjustments and the monetary authority is engaged in responding aggressively to deviations of inflation from its fixed target. In the emergency budget case, the fiscal authority creates and emergency budget that is not expected to be balanced with future surpluses and the central bank adopts a rule with a temporary inflation target meant to accommodate the emergency budget.

Fiscal Orthodoxy Under fiscal orthodoxy, the fiscal authority adjusts government spending $\hat{g}_{t}$, transfers $\hat{z}_{t}$, and tax rates on capital income, labor income, and consumption $\hat{\tau}^{J}$, $J \in\{K, L, C\}$ as follows:

$$
\begin{gathered}
\hat{g}_{t}=\rho_{G} \hat{g}_{t-1}-\left(1-\rho_{G}\right) \gamma_{G} \hat{s}_{b, t-1}, \\
\hat{z}_{t}=\rho_{Z} \hat{z}_{t-1}-\left(1-\rho_{Z}\right) \gamma_{Z} \hat{s}_{b, t-1}+\varepsilon_{t}^{Z}, \\
\hat{\tau}_{t}^{J}=\rho_{J} \hat{\tau}_{t-1}^{J}+\left(1-\rho_{J}\right) \gamma_{J} \hat{s}_{b, t-1},
\end{gathered}
$$

where $\hat{s}_{b, t-1}$ denotes the debt-to-GDP ratio and $\varepsilon_{t}^{Z} \sim N\left(0, \sigma_{z}^{2}\right)$ the shock to transfers. The fiscal authority is credibly committed to repay its obligations by raising taxes and cutting expenditures and this behavior is captured by the values for the reaction parameters $\gamma_{G}, \gamma_{Z}$, and $\gamma_{J}^{*}>0$ that are consistent with Ricardian fiscal policy. 
Under fiscal orthodoxy the central bank is fully committed to respond strongly to inflation deviations from its fixed target $\hat{\pi}_{t}=\ln \frac{\Pi_{t}}{\Pi^{*}}$ with the nominal rate of interest, $\hat{R}_{t}$, on one-period bond. The monetary rule is

$$
\hat{R}_{t}=\rho_{r} \hat{R}_{t-1}+\left(1-\rho_{r}\right)\left[\phi_{\pi} \hat{\pi}_{t}+\phi_{y} \hat{y}_{t}\right]
$$

where the parameter $\phi_{\pi}>1$ so that the Taylor principle is satisfied and monetary policy is active.

Emergency Budget Under the emergency budget strategy, the fiscal authority is committed to repay only a fraction of debt $\hat{s}_{b, t}^{T}<\hat{s}_{b, t}$ by raising taxes and cutting expenditures. No provision is made about how the residual part of debt, $\hat{s}_{b, t}-\hat{s}_{b, t}^{T}$, the emergency budget, will be stabilized:

$$
\begin{gathered}
\hat{g}_{t}=\rho_{G} \hat{g}_{t-1}-\left(1-\rho_{G}\right) \gamma_{G} \hat{s}_{b, t-1}^{T}, \\
\hat{z}_{t}=\rho_{Z} \hat{z}_{t-1}-\left(1-\rho_{Z}\right) \gamma_{Z} \hat{s}_{b, t-1}^{T}+\varepsilon_{t}^{Z}, \\
\hat{\tau}_{t}^{J}=\rho_{J} \hat{\tau}_{t-1}^{J}+\left(1-\rho_{J}\right) \gamma_{J} \hat{s}_{b, t-1}^{T},
\end{gathered}
$$

where $J \in\{K, L, C\}$ and $\varepsilon_{t}^{Z} \sim N\left(0, \sigma_{z}^{2}\right)$. The parameters $\gamma_{G}>0, \gamma_{Z}>0$, and $\gamma_{J}>0$ are consistent with Ricardian fiscal policy. The restrictions on these parameters imply that the government is committed to raise enough fiscal resources to cover the amount of debt $\hat{s}_{b, t-1}^{T}$. On the other hand, the fiscal authority is not committed to move primary surpluses to cover the amount of debt exceeding the target amount $\hat{s}_{b, t-1}^{T}$.

The fiscal stimulus is captured by a large shock to transfers $\left(\varepsilon_{t}^{Z}>0\right)$. This can be interpreted as a situation in which the fiscal authority introduces an emergency budget to finance the debt-to-GDP resulting from the fiscal stimulus. The fiscal authority is committed to raise primary surpluses to cover its pre-COVID debt as Ricardian policy prescribes. Below we will explain how the level of debt $s_{b, t}^{T}$ that the fiscal authority is committed to repay is determined.

The monetary authority fully cooperates with the fiscal authority by allowing inflation to temporary increase above the long-term target. This can be done by introducing a temporary time-varying inflation target $\hat{\pi}_{t}^{T}$ to accommodate the inflation needed to stabilize the emergency budget $\left(\hat{s}_{b, t}-\hat{s}_{b, t}^{T}\right)$, i.e., the fraction of the debt-to-GDP ratio that is not fiscally backed. The monetary authority responds to deviations of inflation from this temporarily higher target $\hat{\pi}_{t}^{T}$. Thus, movements in the nominal interest rate $\hat{R}_{t}$ will be commensurated to the deviations of inflation from the temporary inflation target, and not to the deviations 
from the fixed long-term target as in the fiscal orthodoxy case. This leads us to a Taylor rule modified to account for the presence of the emergency budget:

$$
\hat{R}_{t}=\rho_{r} \hat{R}_{t-1}+\left(1-\rho_{r}\right)\left[\phi_{\pi}\left(\hat{\pi}_{t}-\hat{\pi}_{t}^{T}\right)+\phi_{y} \hat{y}_{t}\right]
$$

where $\phi_{\pi}>1$ implies active monetary policy. This monetary rule implies that the central bank reacts only to inflation deviations from the time-varying target $\hat{\pi}_{t}^{T}$. In equilibrium, this target is larger than the fixed inflation objective used in the fiscal orthodoxy case, implying that on average the central bank will tolerate a higher level of inflation. This strategy is justified by the need to let inflation rise by the exact amount necessary to stabilize the debt ascribed to the emergency budget $\hat{s}_{b, t}-\hat{s}_{b, t}^{T}$. At the same time, the central bank retains the commitment to fight excessively high levels of inflation and to return to the long-term target once the emergency budget is reabsorbed. In the next section, we will discuss how to characterize these temporary inflation targets.

The idea of the emergency budget presents some similarities with President Roosevelt's New Deal. President Roosevelt ran his Presidential campaign as fiscally conservative, but in 1933, he openly argued that there were two separate budgets. A regular federal budget for which a pledge was made to cut specific outlays. An emergency budget, which was needed to defeat the depression and which was unbalanced. In April of the same year, the United States abandoned the gold standard, disanchoring the value of the dollar from gold in a way to gain leeway in the conduct of monetary policy. Eggertsson (2008) and Jacobson, Leeper, and Preston (2019) argue that these policy decisions played a key role in ending the Great Depression.

Temporary Targets of Debt-to-Output Ratio and Inflation The fiscal and monetary rules under the emergency-budget strategy require policymakers to provide temporary targets for the debt-to-GDP ratio and inflation, which we denoted with $s_{b, t}^{T}$ and $\pi_{t}^{T}$. These targets define the amount of the debt-to-GDP ratio not backed by future fiscal adjustments and the amount of inflation that the central bank needs to forgo to stabilize such amount. We construct a shadow economy to characterize these targets.

The same equations that characterize the equilibrium of the actual economy also govern the shadow economy. The only point of departure is that the initial \$2.6-trillion dollars shock to transfers does not affect the shadow economy. All other shocks, including the shock that have started the recession, would hit both the actual economy and the shadow economy. Furthermore, in the shadow economy fiscal and monetary policies are Ricardian and respond to inflation and previous period's debt-to-GDP ratio of the shadow economy. 
Hence, by construction, the shadow economy returns the dynamics of inflation and debt-toGDP ratio in the counterfactual scenario in which the fiscal stimulus was not undertaken and so the monetary- and fiscal-policy mix would be Ricardian.

It also follows that the debt-to-GDP ratio in the shadow economy precisely isolates the portion of debt that does not depend on the fiscal stimulus and hence is not financed with the emergency budget. To balance that portion of the debt-to-GDP ratio, the fiscal authority is fully committed to raise future surpluses. Thus, the target debt-to-GDP ratio $\hat{s}_{b, t-1}^{T}$ in the fiscal rules (7)-(9) corresponds to the debt-to-GDP ratio in the shadow economy, which we denote by $\hat{s}_{b, t}^{*}$.

The fiscal authority will not be responsible to adjust taxes or expenditures to stabilize the remaining fraction of debt, which is given by the difference $\hat{s}_{b, t-1}-\hat{s}_{b, t-1}^{T}$, where $s_{b, t-1}$ is the debt-to-GDP ratio in the actual economy. It should be noted that the size of the emergency budget to finance the debt-to-GDP ratio resulting from the $\$ 2.6$-trillion fiscal stimulus is endogenous, as the actual size of the debt-to-GDP ratio to be stabilized depends on the effects of the stimulus on the equilibrium outcome (e.g., output, tax revenues, transfers, etc.) in the actual economy. This makes the fraction of debt that the government is not committed to stabilize with future fiscal adjustments to vary over time. In other words, policymakers are not committed to repay the increase in the debt-to-GDP ratio resulting from the fiscal stimulus. However, they remain committed to raise taxes and lower expenditures to stabilize the pre-existing amount of the debt-to-GDP ratio.

We now turn our attention to the temporary state-dependent inflation target in the monetary rule (10). The central bank needs to choose this temporary target so that inflation can rise just by the amount necessary to stabilize the emergency budget, $\left(\hat{s}_{b, t-1}-\hat{s}_{b, t-1}^{T}\right)$. Again, the shadow economy we have defined in this section comes handy. Indeed, the difference between the equilibrium inflation in the actual economy and the equilibrium inflation in the shadow economy can be shown to give us the right amount of inflation needed to wear away the fraction of the debt financed with the emergency budget. Therefore, we write the temporary inflation target $\pi_{t}^{T}$ in the rule of the actual economy as the difference between the two equilibrium inflation rates in the two economies; that is, $\hat{\pi}_{t}^{T} \equiv \hat{\pi}_{t}-\hat{\pi}_{t}^{*}$, where $\pi_{t}^{*}$ denotes the equilibrium inflation rate in the shadow economy.

Endowed with these intuitions, we then can rewrite the monetary and fiscal rules (7)-(10) as follows

$$
\begin{gathered}
\hat{g}_{t}=\rho_{G} \hat{g}_{t-1}-\left(1-\rho_{G}\right) \gamma_{G} \hat{s}_{b, t-1}^{*}, \\
\hat{z}_{t}=\rho_{Z} \hat{z}_{t-1}-\left(1-\rho_{Z}\right) \gamma_{Z} \hat{s}_{b, t-1}^{*}+\varepsilon_{t}^{Z}, \\
\hat{\tau}_{t}^{J}=\rho_{J} \hat{\tau}_{t-1}^{J}+\left(1-\rho_{J}\right) \gamma_{J} \hat{s}_{b, t-1}^{*},
\end{gathered}
$$


with $J \in\{K, L, C\}$ and

$$
\hat{R}_{t}=\rho_{r} \hat{R}_{t-1}+\left(1-\rho_{r}\right)\left[\phi_{\pi} \hat{\pi}_{t}^{*}+\phi_{y} \hat{y}_{t}\right]
$$

where the starred variables are defined in the shadow economy described earlier.

Note that these rules belong to the broader class of shock-specific rules introduced by Bianchi and Melosi (2019). To see this, note that policymakers respond with different strength to the changes in debt, inflation, and output resulting from the large fiscal stimulus shock. Following a positive transfer shock to be financed with the emergency budget strategy, the temporary inflation target of the central bank will increase, as we shall show. Such increase in the target would lead the central bank to respond more aggressively when inflation is below the fixed long-term target and to be more accommodative when inflation runs above the fixed long-term inflation target. Interestingly, the FOMC has discussed the suitability of a similar asymmetric approach to inflation stabilization in its meeting of 28 and 29 January 2020 as reported by the minutes of that meeting on page 10. Bianchi, Melosi, and Rottner (2019) show that this type of asymmetric monetary rules re-anchor inflation expectations to the long-term inflation objective and correct the deflationary bias arising in a low interest rate environment.

Loglinear Approximation and Model Solution The model is log-linearized around the steady state (transfers and primary surplus are linearized). Once the equations of the shadow economy are added to the equations of the actual economy, including the rules expressed

as shock-specific rules as in equation (11)-(14), the model can be solved using off-the-shelf methods for linear rational expectations models. Appendix A presents the complete set of linearized equations.

\section{Calibration}

The model is calibrate to the U.S. economy at quarterly frequency, relying largely on the estimates by Leeper, Traum, and Walker (2017) over the period 1955Q1 through 2014Q2. Calibrated parameter values, along with their description and source are reported in Table 1. Starting with the parameters that characterize household preferences, we follow Leeper, Traum, and Walker (2017) in setting the inverse Frish elasticity $\xi$ to 1.77, the external habit parameter $\theta$ to 0.99 and the coefficient governing the substitutability between private and public consumption $\alpha^{G}$ to -0.24 . The discount factor $\beta$ is set to 0.999 in order to match a real interest rate of $1.1 \%$. We follow Kaplan, Violante, and Weidner (2014) and we set the 


\begin{tabular}{|c|c|c|c|}
\hline \multicolumn{4}{|c|}{ Calibration } \\
\hline Parameters & Description & Value & Target/source \\
\hline \multicolumn{4}{|l|}{ Preferences } \\
\hline$\beta$ & Discount factor & 0.999 & Real rate $1.4 \%$. (FOMC SEP) \\
\hline$\xi$ & Inverse Frisch elasticity & 1.770 & Leeper et al. (2017) \\
\hline$\theta$ & Habit formation & 0.990 & Leeper et al. (2017) \\
\hline$\alpha^{G}$ & Substitutability of private vs. gov. consumption & -0.240 & Leeper et al. (2017) \\
\hline \multicolumn{4}{|c|}{ Frictions and technology } \\
\hline $100 \gamma$ & Steady-state log growth rate of technology & 0.250 & Leeper et al. (2017) \\
\hline$\mu$ & Share of hand-to-mouth households & 0.11 & Kaplan et al. (2014) \\
\hline$\alpha$ & Elasticity in production function & 0.330 & Leeper et al. (2017) \\
\hline$\delta$ & Capital depreciation rate & 0.025 & Leeper et al. (2017) \\
\hline$s$ & Investment adjustment cost & 5.460 & Leeper et al. (2017) \\
\hline$\psi$ & Capital utilization cost & 0.160 & Leeper et al. (2017) \\
\hline$\omega_{p}$ & Price Calvo parameter & 0.920 & Leeper et al. (2017) \\
\hline$\omega_{w}$ & Wage Calvo parameter & 0.910 & Leeper et al. (2017) \\
\hline$\chi_{p}$ & Price indexation & 0.060 & Leeper et al. (2017) \\
\hline$\chi_{w}$ & Wage indexation & 0.180 & Leeper et al. (2017) \\
\hline$\eta_{p}$ & Price markup & 0.140 & Leeper et al. (2017) \\
\hline$\eta_{w}$ & Wage markup & 0.140 & Leeper et al. (2017) \\
\hline \multicolumn{4}{|c|}{ Monetary authority } \\
\hline$\phi_{\pi}$ & Interest rate response to inflation & 2.000 & See Section 3 \\
\hline$\phi_{y}$ & Interest rate response to output & 0.100 & See Section 3 \\
\hline$\rho_{r}$ & Interest rate smoothing & 0.710 & Leeper et al. (2017) \\
\hline \multicolumn{4}{|c|}{ Fiscal authority } \\
\hline$\rho$ & Debt maturity decay rate & 0.959 & CBO (2020) \\
\hline$\tau^{L}$ & Steady-state tax rate on labor & 0.186 & Leeper et al. (2017) \\
\hline$\tau^{K}$ & Steady-state tax rate on capital & 0.218 & Leeper et al. (2017) \\
\hline$\tau^{C}$ & Steady-state tax rate on consumption & 0.023 & Leeper et al. (2017) \\
\hline$\rho_{i}$ & Persistence of $\mathrm{G}$, and tax rates $i=G, K, L$ & 0.980 & Estimated \\
\hline$\rho_{Z}$ & Persistence of transfers rule & 0.500 & Calibrated \\
\hline$\gamma_{G}$ & Debt response with $G$ & 0.260 & Leeper et al. (2017) \\
\hline$\gamma_{Z}$ & Debt response with transfers & 0.220 & Calibrated \\
\hline$\gamma_{i}$ & Debt response, for $i=\tau^{K}, \tau^{L}$ & 0.220 & Calibrated \\
\hline$\gamma_{C}$ & Debt response with consumption taxes & 0.000 & See Section 3 \\
\hline \multicolumn{4}{|c|}{ Steady state calibration targets } \\
\hline$s_{g c}$ & Government expenditures to GDP ratio & 0.110 & Leeper et al. (2017) \\
\hline$s_{b}$ & Debt to annualized GDP ratio & 0.600 & Leeper et al. (2017) \\
\hline
\end{tabular}

Table 1: Calibrated values for model parameters and steady-state targets.

share of hand-to-mouth household $\mu$ to match the poor hand-to-mouth consumers $0.11 .^{2}$

The values of all parameters governing technology and the frictions in price and wage setting are also taken from Leeper, Traum, and Walker (2017). Namely, with regards to the technological parameters, the steady state quarterly growth rate of technology $100 * e^{\gamma}$ is set to 0.25 , the elasticity of output to capital in the production function $\alpha$ takes the value of 0.33 , the rate of capital depreciation $\delta$ is set to 0.025 , and the parameters governing the convexity

\footnotetext{
${ }^{2}$ As shown in that paper, including the wealthy hand-to-mouth consumers, who are people owning illiquid assets and short of cash, would increase this parameter to $0.33 \%$. Results would not qualitatively change if we used this larger number.
} 
of the investment adjustment cost function and of the capital utilization cost function are set to 5.46, and 0.16, respectively. As for the parameters related to the pricing frictions, the Calvo parameters for prices and wages are set to 0.92 and 0.91 , respectively, the steady state markups are both set to 0.14 , and the parameters governing indexation are set to 0.06 for prices and 0.18 for wages, respectively.

Steady-state fiscal variables are also implied by the same parameterization as in Leeper, Traum, and Walker (2017). Specifically, the decay rate of the maturity of long-term bonds, $\rho$, is set to 0.9593 to match an average duration of six years estimated by Congressional Budget Office (2020). We also assume a steady state debt to GDP ratio of $60 \%$ (240\% with respect to quarterly GDP). This number is above the historical average. The conclusions of our paper would not be affected by lower values because the emergency budget does not apply to the pre-existing debt. The share of government consumption in GDP is set to the value of 0.11 . The steady-state tax rates on capital, labor and consumption are set to 0.218 , 0.186 and 0.023 , respectively.

Moving to the coefficients that characterize the behavior of the monetary authority, we set the interest rate response to inflation in the monetary regime $\phi_{\pi}$ to the conventional value of 2 , the response to output $\phi_{y}$ to 0.1 and the smoothing coefficient $\rho_{r}$ to 0.71 as estimated by Leeper, Traum, and Walker (2017).

The debt responses of transfers, as well as capital and income tax rates, $\gamma_{Z}, \gamma_{K}$, and $\gamma_{L}$, are set so as to drive the debt-to-GDP ratio to its steady state value of $60 \%$ in twenty years in the case of fiscal orthodoxy. ${ }^{3}$ In doing this, we assume that the adjustment (in deviation from the steady-state value) to achieve this objective is the same across these three fiscal tools. This yields a coefficient for $\gamma_{Z}, \gamma_{K}$, and $\gamma_{L}$ equal to 0.22 . The response of government consumption to the evolution of the debt-to-GDP ratio, $\gamma_{G}$, is set to equal the value estimated by Leeper, Traum, and Walker (2017). The consumption tax rate $\gamma_{C}$ is assumed to be constant. We estimate the serial correlation coefficients in the fiscal rule using the time series constructed by Leeper, Traum, and Walker (2017) and described in their online appendix.

\section{Policy Evaluation}

We initialize the economy with the value of the debt-to-GDP ratio estimated by the CBO for year 2019. We then calibrate the 2020 transfer shock using the CARES act fiscal stimulus

\footnotetext{
${ }^{3}$ After twenty years, the debt-to-GDP ratio is very similar across both policy strategies.
} 
package as shown below. ${ }^{4}$ We then trace the response of the model economy under fiscal orthodoxy and the emergency budget scenarios. Recall that the two cases only differ with respect to the way policymakers finance the increase in the debt-to-GDP resulting from the \$2.6-trillion fiscal stimulus. Technically, this implies that under the emergency budget scenario, the debt-to-GDP ratio in the shadow economy corresponds to the pre-shock debtto-GDP ratio in the actual economy as policymakers address the pre-existing level of debt with Ricardian policies. In what follows, we are interested in taking into account how the initial stock of debt affects the macroeconomic outlook in the two scenarios. Thus, we are not plotting simple impulse response functions to the large transfer shock but we also take into consideration the sizable pre-existing government debt that policymakers aim to repay with higher distortionary taxes or transfers, which lowers the non savers' consumption.

We do not take a stand on the size of the recession due to the COVID-19 outbreak, given that there is still considerable uncertainty around the exact magnitude and duration of the shock. Introducing the COVID-19 shock would not alter our analysis below, which is focused on the difference between the fiscal orthodoxy and emergency budget policy strategies. This is because we assume that the increase of the debt-to-GDP ratio due to the contraction in GDP following the COVID-19 shock will not be financed by the emergency budget. Therefore, policymakers will follow Ricardian policies with respect to this additional debt. Designing an emergency budget to finance the whole fiscal consequences of the COVID-19 shock would require policymakers to fully understand the economic effects of the pandemic as the emergency budget is introduced. We think that at this stage, this is not a plausible assumption.

\subsection{Calibration of Shocks and Initial Conditions}

To calibrate the shock $\varepsilon_{z, t}$ to transfers in 2020, we start from the equation that characterizes the direct effect of transfer shocks on the log deviations of the debt-to-GDP ratio from its own steady state:

$$
\frac{\partial \widehat{s}_{b, t}}{\partial \varepsilon_{z, t}}=\frac{z}{b}\left(1-\rho_{Z}\right)^{-1} \frac{\partial \widehat{z}_{t}}{\partial \varepsilon_{z, t}}
$$

where $\widehat{s}_{b, t}$ denotes the log-deviations of the debt-to-GDP ratio from its steady state level, $z$ and $b$ denote the steady-state detrended transfers and debt, $\hat{z}_{t}$ denotes transfers in deviations from steady state and $\rho_{Z}$ denotes the serial correlation in the transfers rule. Since transfers follow an exogenous $A R(1)$ process in our model, $\left(1-\rho_{Z}\right)^{-1} \frac{\partial \widehat{z}_{t}}{\partial \varepsilon_{z, t}}$ equals the total change in transfers from time $t$ to infinity owing to the time- $t$ shock $\varepsilon_{z, t}$.

\footnotetext{
${ }^{4}$ Although this package also includes an increase in government consumption, most of the fiscal stimulus results in an increase in transfers.
} 
We use the increase in the debt-to-GDP ratio due to the stimulus to calibrate the lefthand side of equation (15) and with the knowledge of $z$ and $b$ we calibrate the magnitude of the shock to transfers as follows:

$$
\frac{\partial \widehat{z}_{t}}{\partial \varepsilon_{z, t}}=\frac{b}{z}\left(1-\rho_{Z}\right) \frac{\partial \widehat{s}_{b, t}}{\partial \varepsilon_{z, t}}
$$

According to the CBO, the U.S. government debt was equal to 16.8 trillions in 2019; 79 percent of the U.S. GDP of the same year. If we add the $\$ 2.6$ trillion stimulus to the 2019 stock of debt, the U.S. debt-to-GDP ratio rises to 89 percent of 2019 GDP.

We use the associated log increase in the debt-to-GDP ratio due to the fiscal stimulus to calibrate the derivative $\partial \widehat{s}_{b, t} / \partial \varepsilon_{z, t}$, which we plug into equation (16) to get the initial size of the shocks to transfers.

We denote the initial debt-to-GDP ratio in both the actual economy and the shadow economy with $\widehat{s}_{b_{0}}^{*}$. We initialize this debt as follows:

$$
\widehat{s}_{b_{0}}^{*}=\ln \left[\frac{s_{b, C B O}}{s_{b}}\right],
$$

where $s_{b, C B O}$ is the CBO estimate of the 2019 U.S. debt-to-GDP ratio (i.e., before the 2020 fiscal stimulus) and $s_{b}$ denotes the steady-state debt-to-GDP ratio, which we set to be equal to $60 \%$. The debt in deviation from its trend is initialized consistently $\left(\hat{b}_{0}^{*}=\widehat{s}_{b, 0}^{*}\right.$ and $\hat{b}_{0}=\widehat{s}_{b, 0}$ as $\hat{y}_{0}$ is assumed to be zero).

\subsection{Fiscal Space}

We present the results of our empirical exercise by plotting the path of key macroeconomic variables as they revert to their stationary equilibrium following a shock to government transfers and starting from an initial condition of government debt that is 19 percentage points above its steady-state equilibrium. Figure 1 represents the dynamics of key macroeconomic aggregates: output, consumption, and investment in the first row, the real interest rate, inflation, and the nominal interest rate in the second row. Figure 2 reports the behavior of the fiscal variables, which include the debt-to-GDP ratio, the primary surplus, and government consumption in the first row, and the tax rate on labor income, the tax rate on capital income, and transfers as a fraction of GDP in the second row. In both figures and for each panel, the dashed black line represents the path under fiscal orthodoxy, that is, assuming that all debt is stabilized by the fiscal authority appropriately raising taxes and cutting on government expenditures. The solid blue line represents instead the case in which the fiscal

authority does not take an explicit responsibility for balancing the $\$ 2.6$-trillion emergency 

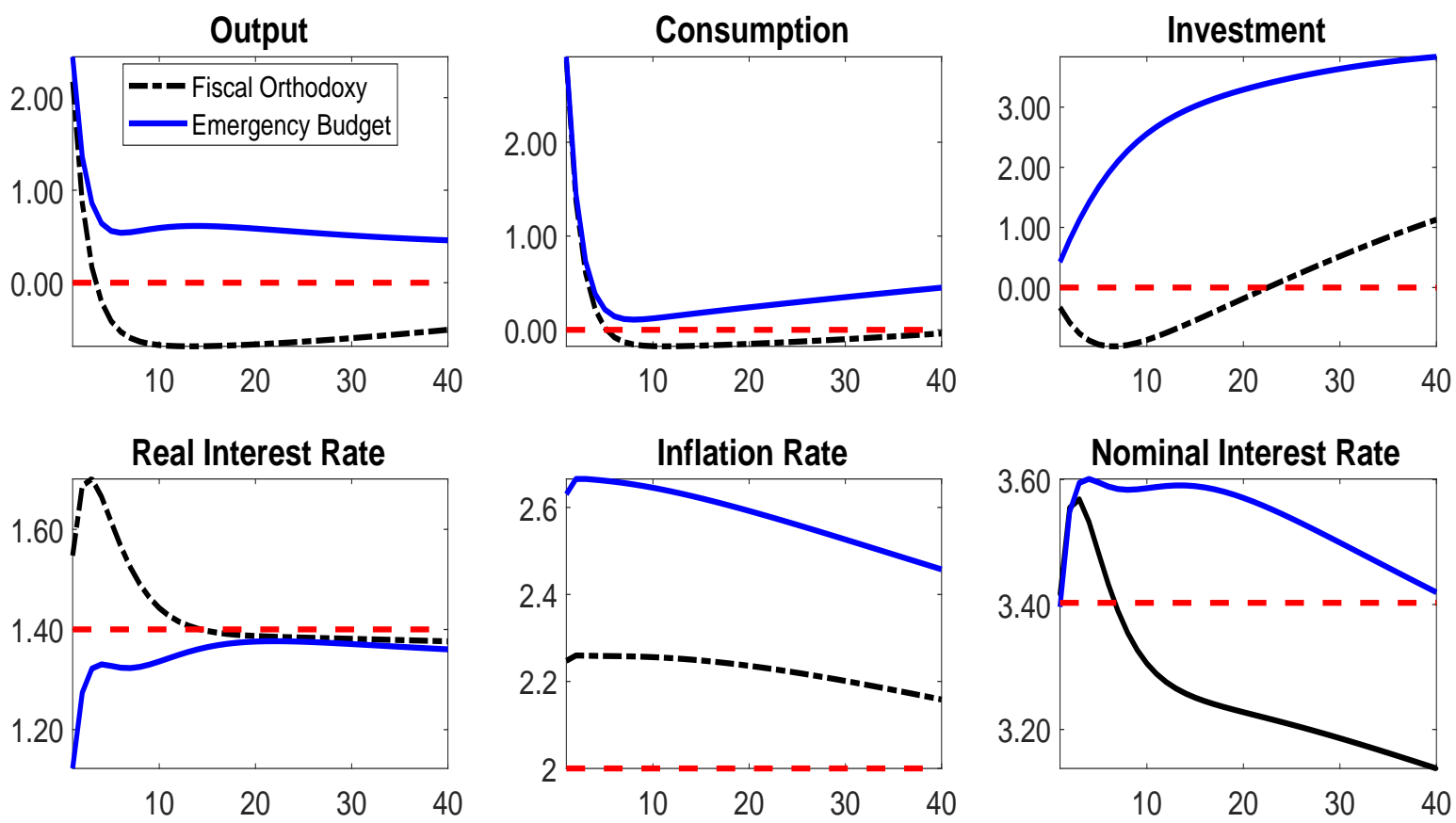

Figure 1: Transitional Dynamics of Key Macroeconomic Aggregates: Fiscal Orthodoxy vs. Emergency Budget. Under the Fiscal Orthodoxy scenario (black dashed line), the entirety of the debt-to-GDP ratio is stabilized by the fiscal authority. In the Emergency budget scenario (solid blue line), the COVID fiscal stimulus is assigned to an emergency budget with no fiscal backing.

budget, in a coordinated attempt with the central bank to use monetary policy to stabilize this fraction of public debt.

Fiscal orthodoxy We first describe the response of the model economy in the case of fiscal orthodoxy (black dashed line). Starting from the behavior of the real macroeconomic aggregates in Figure 1, we observe that the massive fiscal stimulus only produces a shortlived increase in output with a peak impact of about $2 \%$. The expansionary effects of the stimulus persist for three quarters reflecting the rise in consumption from the hand-to-mouth households. The central bank's commitment to fight inflation implies a higher real interest rate and investment falls, as capital taxes rise (see Figure 2).

The main take-away from this exercise is that the fiscal space to respond to the COVID shock is limited. Under fiscal orthodoxy, expectations of future tax rises generate a negative wealth effect which bears negatively on the consumption decision of savers. As a result, the positive impact of the expansionary fiscal policy dies out as the direct effect of transfers on hand-to-mouth consumption fades away. We note that the expansionary effects of the fiscal stimulus in Figure 1 should be considered as an upper-bound to the short-run effects of fiscal transfers, as our environment abstracts from the specific features of the spreading of the 

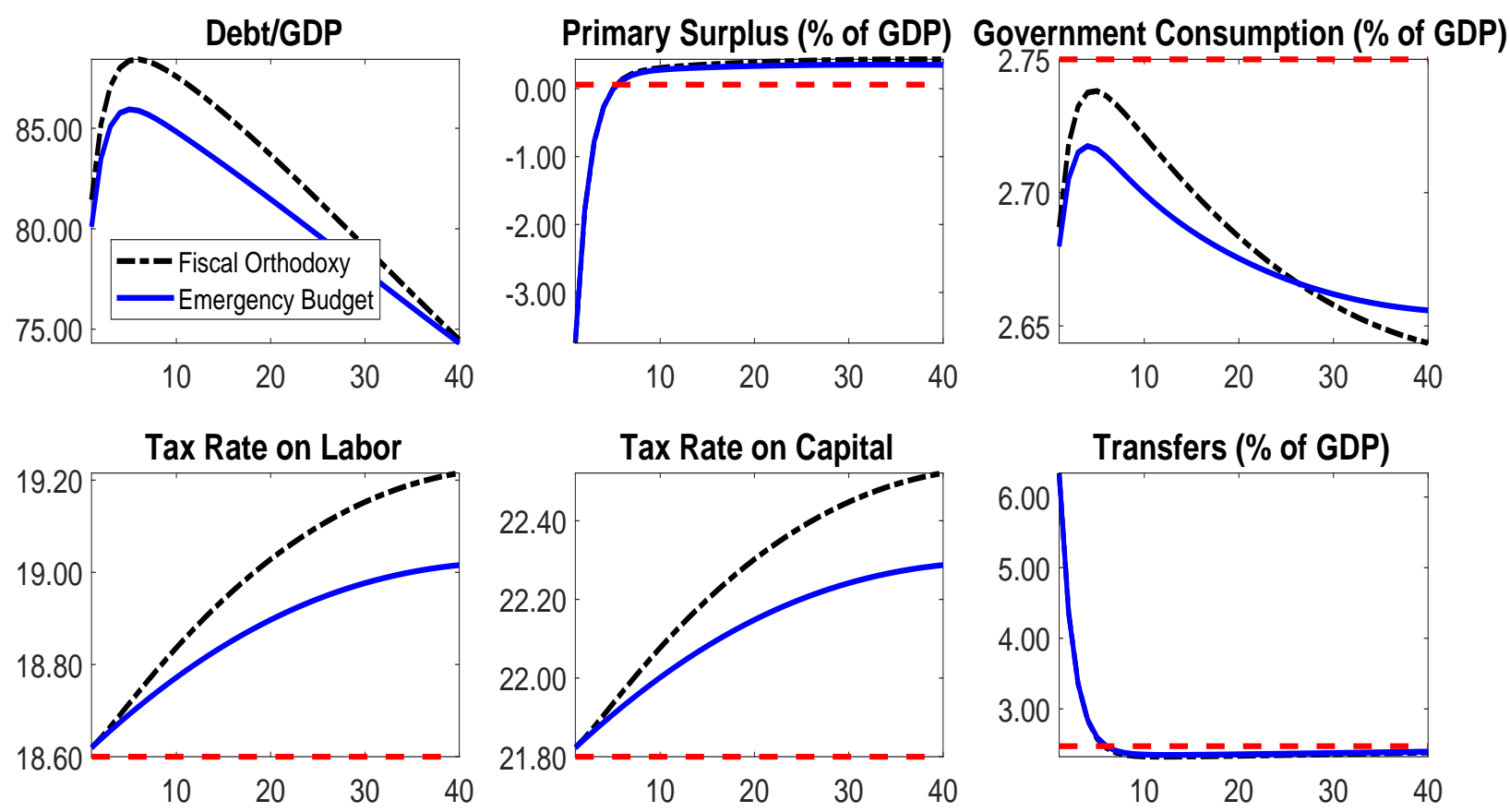

Figure 2: Transitional Dynamics of Fiscal Variables: Fiscal Orthodoxy vs. Emergency Budget. Under the Fiscal Orthodoxy scenario (black dashed line), the entirety of the debt-to-GDP ratio is stabilized by the fiscal authority. In the Emergency budget scenario (solid blue line), the COVID fiscal stimulus is assigned to an emergency budget with no fiscal backing.

COVID-19, such as the lockdown in several sectors of the economy, which would decrease the short-run impact of fiscal multipliers.

Emergency budget In the case where the fiscal and monetary authorities coordinate to stabilize the amount of government debt that directly relates to the emergency budget, the real interest rate falls, as inflation rises. In turn, the persistent fall in real interest rates induces a sharp increase in consumption and investment, which stimulates production for over five years, with a peak on impact of about 2.3\%. Figure 3 illustrates the targets of the coordinated monetary- and fiscal-policy mix that produces an escape from the limited room that the fiscal and the monetary authorities have in isolation. The right panel of the figure plots the actual behavior of the debt-to-GDP ratio in the case of a coordinated response (solid blue line), together with the debt-to-GDP ratio which the fiscal authority is committed to cover with future fiscal adjustments (black dashed line). As explained above, this corresponds to the debt-to-GDP ratio the shadow economy. The difference between the two lines is the amount of debt in the emergency budget which at any point in time remains to be stabilized by the concerted action of the monetary authority. The monetary strategy that achieves this goal is plotted in the left panel of the figure, which depicts the actual rate of inflation (solid blue line) along with the announced temporary time-varying target 

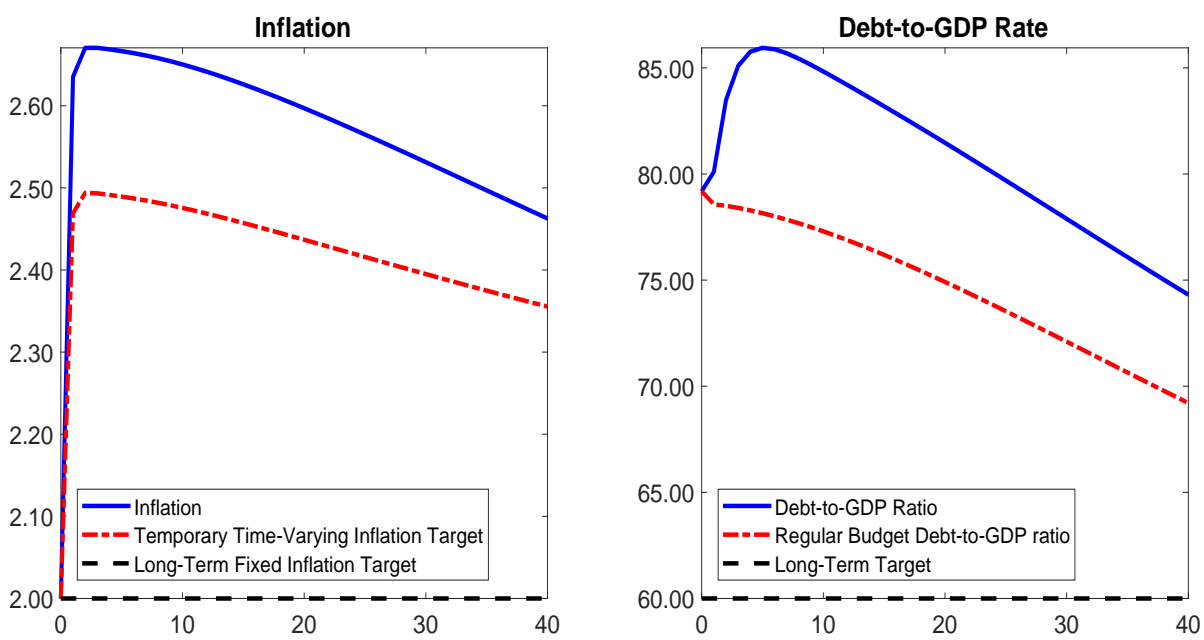

Figure 3: Monetary and Fiscal Policy Targets Under an Emergency Budget. Under the Emergency budget scenario, the COVID fiscal stimulus is ascribed to an emergency budget with no fiscal backing. The emergency budget is given by the difference between the total debt-to-GDP ratio (solid blue line) and the amount of debt-to-GDP ratio backed by future primary surpluses (dashed-dotted red line). The red dashed-dotted line in the left panel corresponds to the temporary state-dependent inflation target.

(dotted-dashed red line).

It is important to notice that the temporary target is less than 50 basis point above the two-percent long-term inflation target and converges to the long-term two-percent goal very sluggishly. This result can be effectively be interpreted as a modest increase in the inflation objective. By raising the target in combination with the adoption of the emergency budget by the fiscal side authority, the central bank achieves the joint objective of enhancing the effectiveness of the fiscal stimulus and correcting a two-decade-long period of below-target inflation. Arguably, the fact that the increase in inflation is necessary in order to stabilize the emergency budget adds credibility to the coordinated policy, unlike an unilateral decision of the central bank that agents might see as easily revertible.

While our model economy features only the initial shock to transfers, we could introduce the standard battery of business cycle shocks (e.g., discount factor shocks, technology shock etc.). So long as policymakers are credibly committed to address any fiscal imbalances generated by these business cycle shocks with Ricardian policies, the temporary inflation target $\pi_{t}^{T}$ in the rule (10) would not be affected by the realization of any of these shocks. ${ }^{5}$

Comparing Fiscal Orthodoxy and Emergency Budget As illustrated in Figure 2, the tax rates on labor, capital and consumption, do not have to rise as much in the case of an emergency budget, as the production boom generated by the coordinated fiscal-monetary policy mix induces a boom in fiscal revenues that contributes to keep the debt-to-GDP ratio

\footnotetext{
${ }^{5}$ Technically, this happens as both the economy and the subeconomy are linear economies and their equilibrium outcomes are equally affected by these shocks.
} 

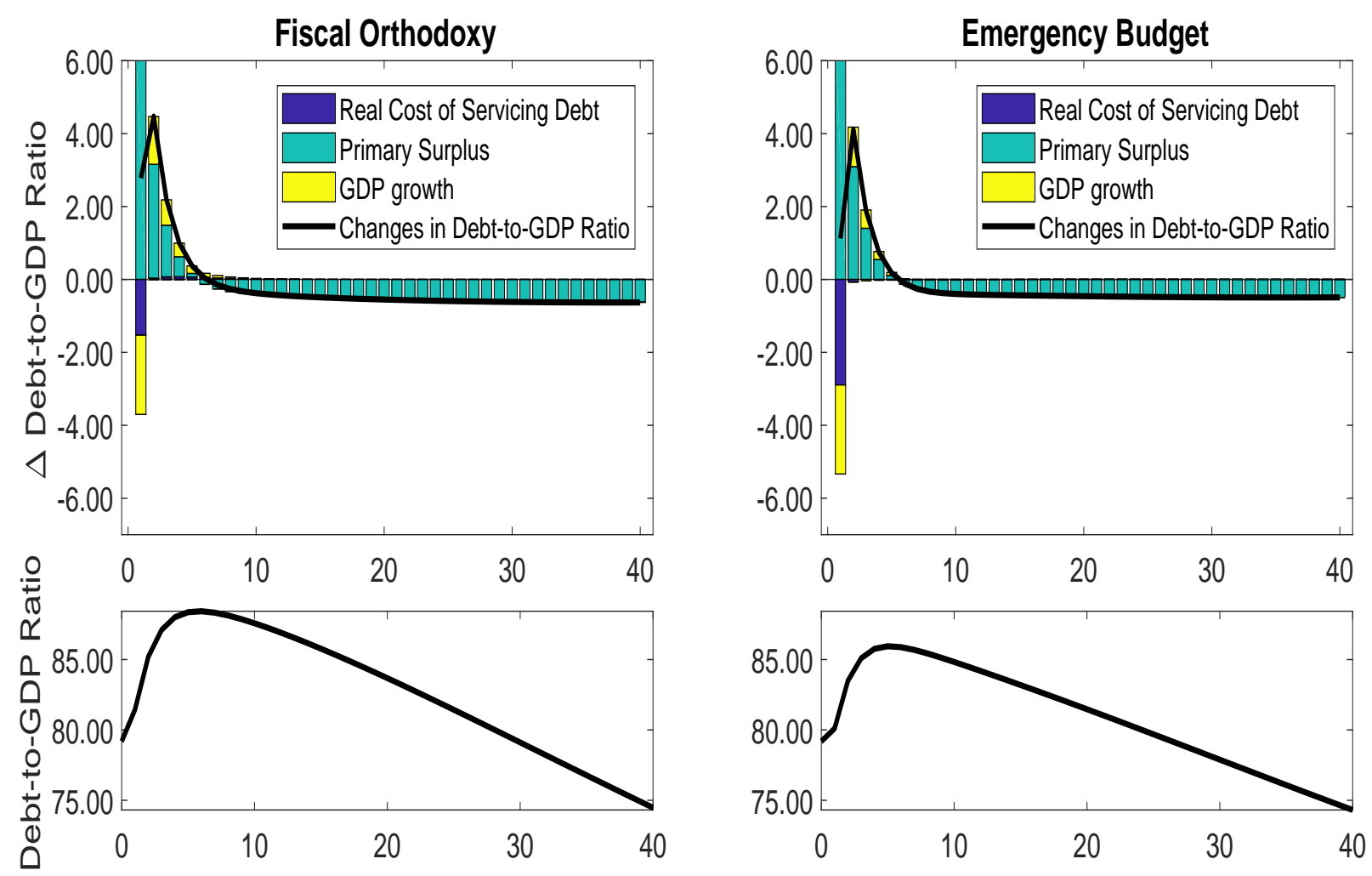

Figure 4: Contributions to Changes in Debt-to-GDP Ratios. The upper panels show the changes in public debt as defined on the left-hand-side of equation (18) following the $\$ 2.6$ trillion fiscal shock. The lower panels show the implied dynamics of the debt-to-GDP ratio.

in check. To further elucidate the underlying mechanism, we consider a decomposition of the per-period change in the debt-to-GDP ratio based on the loglinearized budget constraint:

$$
\begin{aligned}
& \widehat{s}_{b, t}-\beta^{-1} \widehat{s}_{b, t-1}=\underbrace{\left[\frac{\rho}{e^{\gamma}} \hat{P}_{t}^{B}-\beta^{-1}\left(P_{t-1}^{B}+\hat{\pi}_{t}\right)\right]}_{\text {service cost of debt }}-\underbrace{\left[\hat{y}_{t}-\beta^{-1} \hat{y}_{t-1}\right]}_{\text {GDP growth }}
\end{aligned}
$$

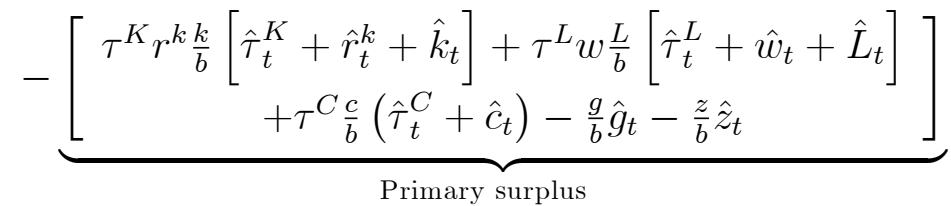

where on the right hand side the first term within square brackets captures the effect of the real cost of servicing debt on the change in the debt-to-GDP ratio, the second term captures the effects of output growth, and the last five terms define the contribution of the primary surplus.

Figure 4 provides the decomposition for the fiscal orthodoxy (left plot) and the emergency budget (right plot) scenarios. In both cases, the enormous increase in primary deficits dominates the initial increase in the debt-to-GDP ratio as captured by the teal bars lying 
in the positive territory for the first four quarters. Note that the height of these bars is fairly close across the two policy strategies as the transfers dominate the (negative) change in the primary budget in these early periods. However, the initial increase in the debt-toGDP ratio is very different across the two scenarios. This is due to two reasons. First, the boom is stronger and more prolonged under the emergency budget (see the yellow bars). Second, the dramatic fall in the real cost of the debt (the blue bars) is more pronounced when policymakers adopt the emergency-budget approach, which contributes to lowering the debt-to-GDP ratio in the first period and to reduce its growth rate over the following three periods. This effect is a combination of low real interest rates and the jump in the long term nominal interest rate that reduces the prices of long term bonds. The figure shows that when the emergency budget is adopted, the debt-to-GDP ratio reaches a peak value of about $86 \%$ compared to a value of about $89 \%$ in the case of orthodoxy. The difference is due to the improved ability by policymakers to lower the real interest rate, with beneficial effects on growth and inflation, in the case of the emergency budget.

In the long run, across both scenarios policymakers are raising primary surpluses to stabilize the pre-existing stock of debt, for which they are committed to repay through fiscal adjustments. These actions are captured by the teal bars lying in the negative territory from period 5 and on. These fiscal adjustments are costly and lower output as shown in Figure 1. It is important to notice that the better economic performance and the slightly higher inflation in the first four quarters under the emergency budget case leaves policymakers with a slimmer debt-to-GDP ratio in period 5. As a result, the fiscal adjustment is less drastic, which is reflected in shorter teal bars in the right graph. In Figure 1, the more gentle fiscal consolidation was shown to improve output. Even though the fiscal adjustment is less severe, the fact that the emergency-budget policy mix allows policymakers to tidy up the fiscal situation early on implies that debt converges faster to the long-term target when the emergency budget is adopted.

\subsection{Helicopter Money}

In the case of the emergency budget depicted in Figure 1, the coordinated action of the fiscal and monetary authorities wears away a well-defined and limited portion of the debt-to-GDP ratio by causing a gradual rise in inflation that the central bank accommodates. What sparks inflation is the announcement of a new fiscal and monetary policy mix, which is reflected in the projected paths of the fiscal instruments, i.e. tax rates, transfers and government expenditures, and of the temporarily asymmetric inflation target. Inflation expectations jump upon the implementation of the coordinated policy mix, leading to an immediate 
decline in real interest rates.

The model abstracts from money, as the monetary policy rule is defined in terms of an interest rate policy. Nevertheless, it can be interesting to understand how our analysis relates to the discussion on helicopter money, i.e., the assumption of a fiscal transfer of cash to households financed by an increase in money growth. The policy we analyze clearly shares some elements of commonality with the discussion on helicopter money. However, whatever happens to money in equilibrium is not necessary to pinpoint the source of inflation, which lies in the agreement between the fiscal and the monetary authorities about how to finance an existing fiscal burden. Money is a tool, and its equilibrium behavior that is consistent with a given policy mix can be made explicit and traced, with no consequences for the equilibrium dynamics reported in the previous sections.

The simplest way to introduce money in the model, is to assume it in the utility function. For instance, we could postulate the function

$$
\mathcal{U}_{t}^{S}=\left(\ln \left(C_{t}^{* S}(j)-\theta C_{t-1}^{* S}\right)-L_{t}^{S}(j)^{1+\xi} /(1+\xi)+\zeta \ln \left(\frac{M_{t}}{P_{t}}\right)\right)
$$

where $M_{t}$ denotes money and $\zeta>0$. At the same time, seigniorage revenues derived from money creation would need to be added to the government budget constraint, yielding:

$$
\tau_{t}^{K} R_{t}^{k} K_{t}+\tau_{t}^{L} W_{t} L_{t}+\tau_{t}^{C} P_{t} C_{t}+\left[P_{t}^{B} B_{t}-\left(1+\rho P_{t}^{B}\right) B_{t-1}\right]+M_{t}-M_{t-1}=P_{t} G_{t}+P_{t} Z_{t}
$$

which implies that nominal government expenditures or transfers can be financed by an increase in the stock of money. Assuming for simplicity that no utility is derived from government consumption such that $C_{t}^{* S}=C_{t}^{S}$, that there are no habits in consumption $(\theta=0)$, that there is no growth in steady state $(\gamma=0)$, utility maximization yields the following demand function for real money balances, after substituting for the Euler equation:

$$
\frac{M_{t}}{P_{t}}=\zeta\left[\frac{1}{C_{t}}\left(1-\frac{1}{R_{t}}\right)\right]^{-1},
$$

which shows the standard result that real money demand is positively related to consumption and negatively related to the interest rate. Equation (20) implies that for a given interest rate set by the central bank, and for a given level of aggregate consumption and prices at time $t$, the supply of money $M_{t}$ has to adjust to satisfy the demand for real money balances. In the case of the emergency budget depicted in Figure 1, the path of the price level and of consumption relative to the case of fiscal orthodoxy, implies that the supply of money has to increase to satisfy the demand function in Eq. (20). This increase in the stock of money generates seigniorage revenue for the government, which can be used to finance cash 
transfers to the households in Eq.(19) or alleviate the fiscal burden. In both cases, the analysis presented above would not significantly change given that the equilibrium path is pinned down by the interaction between the fiscal rules and the Taylor rule, and not by the precise path of money supply.

In a related paper, Galí (2019) compares the effectiveness of fiscal policy under debt financing vs. money financing, finding larger multipliers in the latter case. Galí (2019) also finds that the relative effectiveness of money financing relative to debt financing is reduced in the presence of the zero lower bound (ZLB). In our analysis of the emergency budget reported in Figure 1 the presence of the ZLB is not a constraint to the effectiveness of the coordinated policy mix analyzed in this paper. Rather, the coordination between the fiscal and the monetary authorities could in principle be helpful to escape the ZLB by creating expectations of higher inflation, which is immediately reflected in higher nominal interest rates. The difference stems from the assumption in Galí (2019), that while dropping money from the helicopter, the monetary authority keeps the inflation target at zero. In our analysis instead, the inflation target is temporarily raised with the explicit intent of reducing the burden of the debt.

\section{Post-COVID Environment and Central Bank Inde- pendence}

The coronavirus outbreak will have important consequences for the US economy. One important legacy will certainly be a further increase in the amount of government debt. As shown in the previous sections, a large debt-to-GDP ratio reduces the ability of the fiscal authority to stabilize the economy during downturns. Thus, it is fair to expect that in the years ahead, the fiscal space to contrast recessions will be greatly reduced. This is particularly problematic in a low interest rate environment that limits the tools available for the Federal Reserve to provide accommodation in a recession.

In this section, we consider a post-COVID scenario in which the U.S. debt-to-GDP ratio reaches a record high level, a quite likely outcome absent the coordinated policies discussed above. This large value of debt would only exacerbate the policy impasse analyzed in the previous sections. If the policy standstill reaches the point where the public loses confidence in the ability of the central bank to effectively stabilize the economy in a recession, the central bank could get under further scrutiny, which could threaten its independence. Furthermore, if the private sector also loses confidence about the fiscal authority's ability or willingness to raise sufficient primary surpluses to back the large stock of debt, inflationary pressure would 

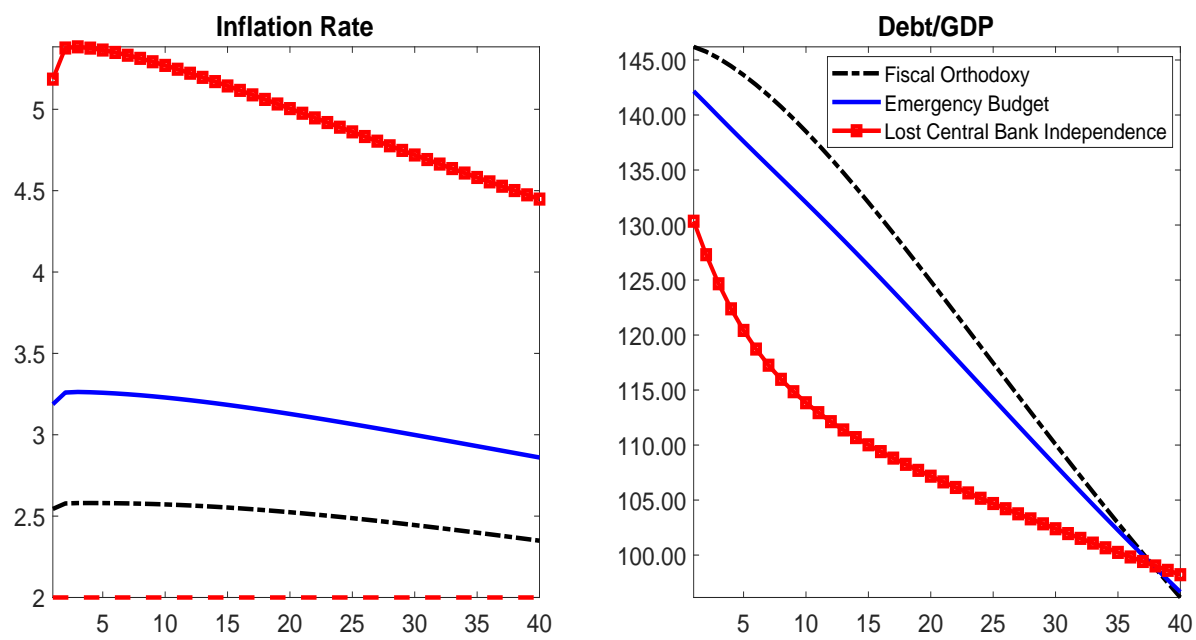

Figure 5: Post-COVID scenario: Inflation and Debt Dynamics under the assumption that the large post-COVID recession public debt will be addressed with (i) Fiscal Orthodoxy, (ii) an Emergency Budget 20\% of the pre-existing debt will be ascribed to, and a Tout Court Switch to Fiscally-Led Regime, implying a sudden loss of central bank's independence (Lost Central Bank Independence).

arise, as agents turn to the central bank for a possible solution.

Under these circumstances, the central bank would be left with the following two options. One possibility is that it tries to reign in inflation by aggressively raising interest rates. Bianchi and Melosi (2019) show that this choice might in fact backfire if agents expect that the central bank will lose its independence. In this case the economy could enter a vicious spiral of stagflation and further debt accumulation. This happens as tightening monetary policy raises the debt-to-GDP ratio both directly, by increasing the cost of servicing the debt, and indirectly, by driving the economy into a recession. If agents expect that eventually the central bank will have to follow the directives of the fiscal authority, the increased fiscal burden would generate a further increase in inflation, as opposed to a decline.

The second possibility is that the central bank forgoes the goal of inflation stabilization. We contrast this scenario with the case in which the monetary and fiscal authorities coordinate to create an emergency budget, which implicitly circumscribes the increase of inflation that the central bank needs to accommodate. By delimitating the amount of debt that is not fiscally backed, this plan effectively preserves the central bank's long-run goals and independence. We consider a post-COVID scenario, assuming that the initial stock of debt will reach $150 \%$ of GDP. The underlying assumption is that policymakers have not implemented the coordinated strategy yet. Consistently with this assumption, the emergency budget rule now consists of assigning a certain fraction of the existing, larger debt to the emergency budget.

The results of this exercise are shown in Figure 5. The solid red line with square markers indicates the dynamics of inflation and the debt-to-DGP ratio if the central bank is no 


\begin{tabular}{cccc}
\hline \hline \multicolumn{3}{c}{ Unconditional Volatility } \\
\hline \multirow{3}{*}{ Inflation } & Fiscal Orthodoxy & Emergency Budget & Lost Central Bank Independence \\
Output & 0.1561 & 0.1561 & 0.2605 \\
\hline \hline
\end{tabular}

Table 2: Unconditional standard deviation of inflation and output under the assumption that the fiscal and monetary policy mix is monetary led (Fiscal Orthodoxy), is coordinated over an emergency budget (Emergency Budget), and fiscally led (Lost Central Bank Independence). We add the shocks estimated by Leeper, Traum, and Walker (2017) to the model.

longer independent from the fiscal authority, which is modeled as a tout-court switch to the Fiscally-led regime (left and right panels, respectively). In this case, the fiscal authority is not expected to implement the fiscal adjustments that are required to head back to the $60 \%$ steady-state debt-to-GDP target, and all adjustments of the debt-to-GDP ratio are due to the inflation created by the monetary authority. ${ }^{6}$ The cost of such policy is a large and persistent rise of inflation, with a peak of $6 \%$ in the second quarter. After 10 years, inflation is still around $4.5 \%$, well above $3 \%$, the peak of inflation observed in the case of the emergency budget (blue line). The larger rate of inflation and the associated drop in real interest rates imply a faster convergence of the debt-to-GDP ratio to its long run target under the Fiscally-led policy mix.

The high and persistent increase in inflation is not the most damaging outcome of the loss of central bank independence. A tout court switch to the Fiscally-led policy mix also implies a change in the way future shocks will be handled. Table 2 reports the unconditional standard deviation for inflation and output for three cases: Fiscal Orthodoxy, Emergency Budget, and Lost Central Bank Independence when the full set of shocks in the estimated model by Leeper, Traum, and Walker (2017) are added. It is immediate to see that this last scenario implies a drastic increase in macroeconomic volatility with respect to Fiscal orthodoxy. This is because now the monetary authority is supposed to accommodate all fluctuations in the debt-to-GDP ratio. Instead, the emergency budget rule preserves longrun macroeconomic stability because it separates an exceptional policy intervention from the problem of long-run fiscal stability. Once the initial shock is reabsorbed, the economy naturally returns to the pre-crisis policy mix in which the fiscal burden is responsibility of the fiscal authority.

Policymakers could also decide to adopt the emergency budget framework to systematically intervene during those recessions that are large enough to push the economy to the zero lower bound. For example, policymakers could decide to ascribe the expenses incurred during these exceptionally large recessions to the emergency budget. In this case, macroeconomic volatility under the emergency budget policy framework would be even lower than

\footnotetext{
${ }^{6}$ Technically, we restrict the interest rate response to inflation, as well as the policy parameters governing the response of all fiscal instruments to lagged debt-GDP to zero.
} 
under Fiscal orthodoxy. This is because the emergency budget would act as an automatic stabilizer, increasing inflation expectations every time that the central bank loses its ability to act. The increase in inflation expectations would determine a drop in the real interest rate and, consequently, a smaller recession and no deflation. Thus, the emergency budget would compensate the limits of monetary policy in a low interest rate environment and reduce the overall volatility of the economy in response to very large shocks. At the same time, when the economy is not at the zero lower bound, debt would be fully backed by fiscal interventions, retaining the advantages of fiscal discipline. These two mechanisms combined would lead to lower macroeconomic volatility.

In the analysis above, we abstracted from two considerations that would arguably make a switch to the Fiscally-led regime even more damaging. First, we have not considered the political economy implications of such a policy change. In a nutshell, it is easy to imagine that once the fiscal authority becomes the leading authority, there might be incentives to increase spending, given that the fiscal authority would not bear the cost of the necessary adjustments. This would arguably cause an inflationary bias with roots due to the lack of fiscal discipline (see Persson and Tabellini 2002 for seminal contributions on this topic). Second, while the emergency-budget coordinated strategy causes only a moderate increase in inflation and no increase in long-run volatility, a tout court switch to the Fiscally-led policy mix would have much more important consequences, as shown above. Thus, it is quite possible that firms would react to such an important policy change by increasing the frequency of price adjustment, resulting in an even larger increase of inflation.

Finally, we analyzed the effects of an immediate change to the Fiscally-led policy mix, resulting in a sudden jump in inflation. The large increase in inflation could also materialize more gradually if agents slowly revise their expectations about the ability of the fiscal authority to stabilize debt. In that case, inflation could experience a run-up and accelerating behavior similar to what was observed in the 1970s (Bianchi and Melosi 2013). Once inflation is out of control, only a drastic change in the monetary-fiscal policy mix like the one experienced by the US economy in the early 1980s would succeed in bringing inflation down. This would be a costly adjustment, as agents would take time to revise their beliefs about the monetary-fiscal policy mix. The coordinated strategy would help in avoiding such a scenario by separating a short-run fiscal intervention from the problem of long-run fiscal stability. 


\section{Conclusions}

We studied a coordinated fiscal and monetary strategy aiming at creating a controlled rise of inflation and an increase in fiscal space in response to the COVID shock. This policy alleviates the constraints currently faced by the two authorities. Record-low long-term nominal interest rates limit the tools of the central bank to stabilize the economy. The large public debt curtails the efficacy of fiscal interventions by inducing expectations of costly fiscal adjustments. Under our coordinated strategy, the fiscal authority ascribes the large fiscal stimulus to an emergency budget with no provisions on how it will be balanced, while the monetary authority allows a temporary increase in inflation. The coordinated strategy enhances the efficacy of the fiscal stimulus planned in response to the COVID pandemic. The strategy results in only moderate levels of inflation and preserves long-run macroeconomic stability by separating long-run fiscal sustainability from a short-run policy intervention.

We show that a coordinated action that delimits the amount of debt that requires central bank intervention may be the lesser of two evils for those concerned about preserving central independence. In fact, the coordinated strategy might be even desirable in and of itself because it would bring about a controlled reflation of the US economy, rendering the central bank the necessary room of maneuver to stabilize the economy in the years ahead.

\section{References}

Bassetto, M. (2002): "A Game-Theoretic View of the Fiscal Theory of the Price Level," Econometrica, 70(6), 2167-2195.

Benhabib, J., S. Schmitt-Grohe, And M. Uribe (2002): "Avoiding Liquidity Traps," Journal of Political Economy, 110(3), 535-563.

Bianchi, F., And C. Ilut (2017): "Monetary/Fiscal Policy Mix and Agents' Beliefs," Review of Economic Dynamics, 26, 113-139.

Bianchi, F., And L. Melosi (2013): "Dormant Shocks and Fiscal Virtue," in NBER Macroeconomics Annual 2013, Volume 28, NBER Chapters, pp. 1-46. National Bureau of Economic Research, Inc.

(2017): "Escaping the Great Recession," American Economic Review, 107(4), 1030 $-58$.

(2019): "The dire effects of the lack of monetary and fiscal coordination," Journal of Monetary Economics, 104, 1-22.

Bianchi, F., L. Melosi, and M. Rottner (2019): "Hitting the Elusive Inflation Target," NBER working paper. 
Christiano, L. J., M. Eichenbaum, and C. L. Evans (2005): "Nominal Rigidities and the Dynamic Effects of a Shock to Monetary Policy," Journal of Political Economy, 113(1), $1-45$.

Cochrane, J. H. (1998): "A Frictionless Model of U.S. Inflation," in NBER Macroeconomics Annual 1998, ed. by B. S. Bernanke, and J. J. Rotemberg, pp. 323-384. MIT Press, Cambridge, MA.

(2001): "Long Term Debt and Optimal Policy in the Fiscal Theory of the Price Level," Econometrica, 69, 69-116.

Congressional Budget Office (2020): "Federal Debt: a Primer," (CBO Publication No. 56165). Washington, DC: Congressional Budget Office.

EGgertsson, G. B. (2008): "Great Expectations and the End of the Depression," American Economic Review, 98(4), 1476-1516.

GaLÍ, J. (2019): "The effects of a money-financed fiscal stimulus," Journal of Monetary Economics, forthcoming.

Hall, G. J., and T. J. Sargent (2011): "Interest Rate Risk and Other Determinants of Post-WWII U.S. Government Debt/GDP Dynamics," American Economic Journal: Macroeconomics, 3(3), 192-214.

Jacobson, M. M., E. M. Leeper, and B. Preston (2019): "Recovery of 1933," NBER Working Papers 25629, National Bureau of Economic Research, Inc.

Kaplan, G., G. Violante, and J. Weidner (2014): "The Wealthy Hand-to-Mouth," Brookings Papers on Economic Activity, 44(1), 77-138.

Leeper, E. M. (1991): "Equilibria Under Active and Passive Monetary and Fiscal Policies," Journal of Monetary Economics, 27, 129-147.

Leeper, E. M., N. Traum, and T. B. Walker (2017): "Clearing Up the Fiscal Multiplier Morass," American Economic Review, 107(8), 2409-2454.

Persson, T., and G. Tabellini (2002): Political Economics: Explaining Economic Policy. The MIT Press.

REIS, R. (2016): "QE in the future: the central bank's balance sheet in a financial crisis," Discussion Papers 1620, Centre for Macroeconomics (CFM).

Sargent, T., and N. Wallace (1981): "Some Unpleasant Monetarist Arithmetic," Federal Reserve Bank of Minneapolis Quarterly Review, Fall, 1-17.

Schmitt-Grohe, S., and M. Uribe (2000): "Price level determinacy and monetary policy under a balanced-budget requirement," Journal of Monetary Economics, 45(1), 211-246.

Sims, C. A. (1994): "A Simple Model for Study of the Determination of the Price Level and the Interaction of Monetary and Fiscal Policy," Economic Theory, 4, 381-399.

Sims, C. A. (2016): "Fiscal policy, monetary policy and central bank independence," in 
Kansas Citi Fed Jackson Hole Conference.

Woodford, M. (1994): "Monetary Policy and Price Level Determinacy in a Cash-inAdvance Economy," Economic Theory, 4, 345-389.

_ (1995): "Price Level Determinacy without Control of a Monetary Aggregate," Carnegie-Rochester Series of Public Policy, 43, 1-46. (2001): "Fiscal Requirements of Price Stability," Journal of Money, Credit, and Banking, 33, 669-728.

- (2003): Interest and prices: Foundations of a theory of monetary policy. Princeton University Press, Princeton, New Jersey. 


\section{A The Log-Linear Model}

The model features a trend in the state of labor-augmenting technological progress. In order to make the model stationary, we define the following variables: $y_{t}=\frac{Y_{y}}{A_{t}}, c_{t}^{* S}=\frac{C_{t}^{* S}}{A_{t}}, c_{t}^{S}=$ $\frac{C_{t}^{S}}{A_{t}}, c_{t}^{N}=\frac{C_{t}^{N}}{A_{t}}, k_{t}=\frac{K_{t}}{A_{t}}, g_{t}=\frac{G_{t}}{A_{t}}, z_{t}=\frac{Z_{t}}{A_{t}}, b_{t}=\frac{P_{t}^{B} B_{t}}{P_{t} A_{t}}, w_{t}=\frac{W_{t}}{P_{t} A_{t}}$, and $\lambda_{t}^{S}=\Lambda_{t}^{S} A_{t}$. We list below the equations of the log-linear model, starting with those that characterize the actualeconomy block.

Production function:

$$
\hat{y}_{t}=\frac{y+\Omega}{y}\left[\alpha \hat{k}_{t}+(1-\alpha) \hat{L}_{t}\right] .
$$

Capital-labor ratio:

$$
\hat{r}_{t}^{K}-\hat{w}_{t}=\hat{L}_{t}-\hat{k}_{t}
$$

Marginal cost:

$$
\widehat{m c_{t}}=\alpha \hat{r}_{t}^{k}+(1-\alpha) \hat{w}_{t}
$$

Phillips curve:

$$
\hat{\pi}_{t}=\frac{\beta}{1+\chi_{p} \beta} E_{t} \hat{\pi}_{t+1}+\frac{\chi_{p}}{1+\chi_{p} \beta} \hat{\pi}_{t-1}+\kappa_{p} \widehat{m c_{t}},
$$

where $\kappa_{p}=\left[\left(1-\beta \omega_{p}\right)\left(1-\omega_{p}\right)\right] /\left[\omega_{p}\left(1+\beta \chi_{p}\right)\right]$.

Saver household's FOC for consumption:

$$
\hat{\lambda}_{t}^{S}=-\frac{e^{\gamma}}{e^{\gamma}-\theta} c_{t}^{* S}+\frac{\theta}{e^{\gamma}-\theta} c_{t-1}^{* S}-\frac{\tau^{C}}{1+\tau^{C}} \hat{\tau}_{t}^{C} .
$$

Public/private consumption in utility:

$$
\hat{c}_{t}^{*}=\frac{c^{S}}{c^{S}+\alpha_{G} g} \hat{c}_{t}^{S}+\frac{\alpha_{G} g}{c^{S}+\alpha_{G} g} \hat{g}_{t} .
$$

Euler equation:

$$
\hat{\lambda}_{t}^{S}=\hat{R}_{t}+E_{t} \hat{\lambda}_{t+1}^{S}-E_{t} \hat{\pi}_{t+1}
$$

Maturity structure of debt:

$$
\hat{R}_{t}+\hat{P}_{t}^{B}=\frac{\rho}{R} E_{t} \hat{P}_{t+1}^{B}
$$

Saver household's FOC for capacity utilization:

$$
r_{t}^{k}-\frac{\tau^{K}}{1-\tau^{K}} \tau_{t}^{K}=\frac{\psi}{1-\psi} \hat{\nu}_{t}
$$


Saver household's FOC for capital:

$\hat{q}_{t}=E_{t} \hat{\pi}_{t+1}-\hat{R}_{t}+\beta e^{-\gamma}\left(1-\tau^{K}\right) r^{k} E_{t} \hat{r}_{t+1}^{k}-\beta e^{-\gamma} \tau^{K} r^{k} E_{t} \hat{\tau}_{t+1}^{K}+\beta e^{-\gamma}(1-\delta) E_{t} \hat{q}_{t+1}$.

Saver household's FOC for investment:

$$
\hat{\imath}_{t}+\frac{1}{(1+\beta) s e^{2 \gamma}} \hat{q}_{t}-\frac{\beta}{1+\beta} E_{t} \hat{\imath}_{t+1}=\frac{1}{1+\beta} \hat{\imath}_{t-1} .
$$

Effective capital:

$$
\hat{k}_{t}=\hat{\nu}_{t}+\widehat{\bar{k}}_{t-1}
$$

Law of motion for capital:

$$
\widehat{\bar{k}}_{t}=(1-\delta) e^{-\gamma} \widehat{\bar{k}}_{t-1}+\left[1-(1-\delta) e^{-\gamma}\right] \hat{\imath}_{t} .
$$

Hand-to-mouth household's budget constraint:

$$
\tau^{C} c^{N} \hat{\tau}_{t}^{C}+\left(1+\tau^{C}\right) c^{N} \hat{c}_{t}^{N}=\left(1-\tau^{L}\right) w L\left(\hat{w}_{t}+\hat{L}_{t}\right)-\tau^{L} w L \hat{\tau}_{t}^{L}+z \hat{z}_{t} .
$$

Wage equation:

$$
\begin{aligned}
\hat{w}_{t}= & \frac{1}{1+\beta} \hat{w}_{t-1}+\frac{\beta}{1+\beta} E_{t} \hat{w}_{t+1}-\kappa_{w}\left[\hat{w}_{t}-\xi \hat{L}_{t}+\hat{\lambda}_{t}^{S}-\frac{\tau^{L}}{1-\tau^{L}} \hat{\tau}_{t}^{L}\right] \\
& +\frac{\chi^{w}}{1+\beta} \hat{\pi}_{t-1}-\frac{1+\beta \chi^{w}}{1+\beta} \hat{\pi}_{t}+\frac{\beta}{1+\beta} E_{t} \hat{\pi}_{t+1} .
\end{aligned}
$$

Aggregate households' consumption

$$
c \hat{c}_{t}=c^{S}(1-\mu) \hat{c}_{t}^{S}+c^{N} \mu \hat{c}_{t}^{N} .
$$

Aggregate resource constraint:

$$
y \hat{y}_{t}=c \hat{c}_{t}+i \hat{\imath}_{t}+g \hat{g}_{t}+\psi^{\prime}(1) k \hat{\nu}_{t} .
$$

Government budget constraint:

$$
\begin{aligned}
& \frac{b}{y} \hat{b}_{t}+\tau^{K} r^{k} \frac{k}{y}\left[\hat{\tau}_{t}^{K}+\hat{r}_{t}^{k}+\hat{k}_{t}\right]+\tau^{L} w \frac{L}{y}\left[\hat{\tau}_{t}^{L}+\hat{w}_{t}+\hat{L}_{t}\right]+\tau^{C} \frac{c}{y}\left(\hat{\tau}_{t}^{C}+\hat{c}_{t}\right) \\
= & \frac{1}{\beta} \frac{b}{y}\left[\hat{b}_{t-1}-\hat{\pi}_{t}-\hat{P}_{t-1}^{B}\right]+\frac{b}{y} \frac{\rho}{e^{\gamma}} \hat{P}_{t}^{B}+\frac{g}{y} \hat{g}_{t}+\frac{z}{y} \hat{z}_{t} .
\end{aligned}
$$


Monetary policy rule under fiscal orthodoxy:

$$
\hat{R}_{t}=\left(1-\rho_{r}\right)\left[\phi_{\pi} \hat{\pi}_{t}+\phi_{y} \hat{y}_{t}\right] .
$$

In the case of the emergency budget instead, the rule above is replaced by:

$$
\hat{R}_{t}=\left(1-\rho_{r}\right)\left[\phi_{\pi} \hat{\pi}_{t}^{*}+\phi_{y} \hat{y}_{t}\right],
$$

where $\hat{\pi}_{t}^{*}$ refers to the rate of inflation in the shadow economy, which is characterized below.

The fiscal rules under the case of orthodoxy are:

$$
\begin{gathered}
\hat{g}_{t}=\rho_{G} \hat{g}_{t-1}-\left(1-\rho_{G}\right) \gamma_{G} \hat{s}_{b, t-1}, \\
\hat{z}_{t}=\rho_{Z} \hat{z}_{t-1}-\left(1-\rho_{Z}\right) \gamma_{Z} \hat{s}_{b, t-1}+\varepsilon_{t}^{Z}, \\
\hat{\tau}_{t}^{J}=\rho_{J} \hat{\tau}_{t-1}^{J}+\left(1-\rho_{J}\right) \gamma_{J} \hat{s}_{b, t-1} .
\end{gathered}
$$

In the case of the emergency budget they are replaced by

$$
\begin{gathered}
\hat{g}_{t}=\rho_{G} \hat{g}_{t-1}-\left(1-\rho_{G}\right) \gamma_{G} \hat{s}_{b, t-1}^{*}, \\
\hat{z}_{t}=\rho_{Z} \hat{z}_{t-1}-\left(1-\rho_{Z}\right) \gamma_{Z} \hat{s}_{b, t-1}^{*}+\varepsilon_{t}^{Z}, \\
\hat{\tau}_{t}^{J}=\rho_{J} \hat{\tau}_{t-1}^{J}+\left(1-\rho_{J}\right) \gamma_{J} \hat{s}_{b, t-1}^{*} .
\end{gathered}
$$

The block of equations that characterize the shadow economy consists in an additional set of equations (21) to (38) plus the rule for the monetary authority (39) and the rules for the fiscal authority (40) to (42), where any variables that refers to the actual economy $x_{t}$ is replaced by the same variable in the shadow economy $x_{t}^{*}$. 